\title{
Existence of Laves Phase in Nb-Hardened Superalloys
}

\author{
Keh-Minn Chang, Hong-Jen Lai and Jeng-Ying Hwang \\ Idustrial Technology Research Institute \\ Materials Research Laboratories \\ Hsinchu, Taiwan, R.O.C.
}

\begin{abstract}
The possibility of forming the topologically close-packed Laves phase has been investigated in various Ni-base superalloy systems that contain a significant amount of $\mathrm{Nb}$. Simplified alloy compositions consisting of various combinations of major alloying elements, including $\mathrm{Cr}, \mathrm{Fe}$, and $\mathrm{Co}$, were prepared; a high level of $\mathrm{Nb}$ was added in each alloys to simulate the dendritic segregation in the real casting process. In addition to the fcc dendrites, the as-cast microstructure through a slow solidification rate developed the regions of eutectic decomposition at the end of solidification. The eutectic regions consisted of only two phases in every alloy studied. The intermetallic phases that formed the eutectic with the fcc Ni matrix were identified by SEM-EDAX, X-ray diffraction, and DTA analysis. The results suggested that Laves phase was not expected to exist in $\mathrm{Ni}-\mathrm{Cr}$-Co base alloys, and that other $\mathrm{Nb}$-hardened superalloys, especially those $\mathrm{Ni}-\mathrm{Cr}-\mathrm{Fe}$ base alloys, would likely develop Laves phase in the $\mathrm{Nb}$ segregated regions during casting. Alloy chemistry theory was proposed to discuss the alloying effect on the existence of Laves phase in Ni base alloy systems. The combination of $\mathrm{Cr}$ and $\mathrm{Fe}$ alloying additions would be the essential criteria to allow Laves phase appeared in a slow solidification process. The DTA analysis indicated that the alloy with the Laves phase had a low eutectic melting point. These important results can provide a comprehensive understanding of what observed in those $\mathrm{Nb}$-strengthened superalloys with complex chemical compositions.
\end{abstract}

\footnotetext{
Superalloys 718, 625, 706 and Various Derlvatives Edited by E.A. Loria

The Minerals, Metals \& Materials Society, 1994
} 


\section{INTRODUCTION}

The addition of $\mathrm{Nb}$ in superalloys led to a series of important alloys being developed, and many of these alloys found some unique and important industrial applications as popular commercial materials [1]. Originally, $\mathrm{Nb}$ in Ni-base superalloys was considered as one of the effective solid solution strengthener, e.g. the 625 alloy. In an fcc $\mathrm{Ni}$ matrix $(\gamma), \mathrm{Nb}$ has a reasonably high solubility, 12 at.\%, and the difference of atomic size between $\mathrm{Nb}$ and $\mathrm{Ni}$ can raise a remarkable mismatch in the $\gamma$ lattice. The essential factor to be controlled in designing this type of supperalloys is how to maintain the maximum $\mathrm{Nb}$ content in the solid solution without forming any intermetallic phase.

The discovery of metastable $\gamma^{\prime \prime}-\mathrm{Ni}_{3} \mathrm{Nb}$ precipitates in the 718 alloy created a new branch of superalloys [2]. The coherency strains associated with the formation of $\gamma^{\prime \prime}$ particles in the $\gamma$ matrix have a substantial strengthening effect. On the other hand, the sluggish aging kinetics of $\gamma^{\prime \prime}$ precipitation allow such a high strength material to be weldable. Many structural castings for gas turbine applications, especially complicate structures and large parts, have shown recently the urgent demand for strong casting superalloys with good weldability $[3,4]$

In both solid solution strengthened and precipitation hardened superalloys, $\mathrm{Nb}$ tends to segregate in the interdendritic area during solidification process. As a result, some undesirable phases may form in the casting products. In most commercial $\mathrm{Nb}$-bearing superalloys, such as 718,625 , and 909 alloys, the solidification process always ends with the formation of a $\mathrm{Nb}$-rich intermetallic Laves phase [5]. The $\gamma /$ Laves eutectics in the cast Nb-hardened superalloys have been well documented in literature, and their detrimental effects on alloy weldability and mechanical properties have been well known.

To design a superalloy free from Laves phase is a significant challenge to metallurgists. The superalloys contain a variety of alloying elements at different concentrations, no consistent thermodynamic data or phase diagram is applicable. Through empirical approach, several new alloys strengthened by $\mathrm{Nb}$ show the indication of the absence of Laves phase. Among them, Rene'220C received many attentions because of its superior properties over 718 alloy [6]. In addition to offering a $50^{\circ} \mathrm{C}$ strength advantage, Rene'220 C has excellent castability and weldability. Recent structural analysis suggested that the alloy was immune to Laves phase formation [7]. Snyder et al. also developed a "Laves Free" superalloy by modifying the alloying element contents of the 718 composition [8]. The tailored alloy is claimed to have properties comparable to 718 alloy. Further modification was made by increasing hardening element levels to improve alloy strength. However, the "High Strength" alloy, designated as PWA1472, was found to contain some trace amount of Laves phase in the as-cast condition [9].

This study tends to identify the basic control of alloying with respect to the formation of Laves phase. The interdendritic segregation of $\mathrm{Nb}$ is known to dominate the solidification behavior. The equilibrium phases that make the final eutectic with $\gamma$ can be readily determined if the alloys contain an excessive amount of $\mathrm{Nb}$ and the ingots are prepared through a reasonably slow casting rate. Different $\gamma$ matrix compositions that simulate various $\mathrm{Nb}$-strengthened superalloys are designed for investigation.

\section{EXPERIMENTALS}

Table 1 lists commercial superalloys that contain a certain amount of $\mathrm{Nb}$ as the strengthening element. Generally, the major alloying additions include $\mathrm{Cr}, \mathrm{Fe}, \mathrm{Co}$, and their combinations. To 
Table $1 \mathrm{Nb}$-strenghtened superalloys

\begin{tabular}{clc}
\hline Designation & \multicolumn{1}{c}{ Composition, wt.\% } & Nb Effects \\
\hline 625 alloy & $\mathrm{Ni}-21.5 \mathrm{Cr}-2.5 \mathrm{Fe}-9 \mathrm{Mo}-3.6 \mathrm{Nb}-.2 \mathrm{Ti}-.2 \mathrm{Al}-.06 \mathrm{C}$ & solid solution \\
706 alloy & $\mathrm{Ni}-16 \mathrm{Cr}-40 \mathrm{Fe}-2.9 \mathrm{Nb}-1.75 \mathrm{Ti}-.25 \mathrm{Al}-.03 \mathrm{C}$ & $\gamma^{\prime \prime}$ precipitates \\
718 alloy & $\mathrm{Ni}-19 \mathrm{Cr}-18.5 \mathrm{Fe}-3 \mathrm{Mo}-5.1 \mathrm{Nb}-.9 \mathrm{Ti}-.5 \mathrm{Al}-.04 \mathrm{C}$ & $\gamma^{\prime \prime}$ precipitates \\
725 alloy & $\mathrm{Ni}-21 \mathrm{Cr}-9 \mathrm{Fe}-8 \mathrm{Mo}-3.5 \mathrm{Nb}-1.5 \mathrm{Ti}-.25 \mathrm{Al}-.01 \mathrm{C}$ & $\gamma^{\prime \prime}$ precipitates \\
909 alloy & $\mathrm{Ni}-13 \mathrm{Co}-42 \mathrm{Fe}-4.7 \mathrm{Nb}-1.5 \mathrm{Ti}-.35 \mathrm{Si}-.01 \mathrm{C}$ & $\gamma^{\prime \prime}$ precipitates \\
Rene'220C & $\mathrm{Ni}-19 \mathrm{Cr}-12 \mathrm{Co}-3 \mathrm{Mo}-5 \mathrm{Nb}-3 \mathrm{Ta}-1 \mathrm{Ti}-.5 \mathrm{Al}-.03 \mathrm{C}$ & $\gamma^{\prime \prime}$ precipitates \\
PWA 1472 & $\mathrm{Ni}-12 \mathrm{Cr}-18 \mathrm{Fe}-3 \mathrm{Mo}-6 \mathrm{Nb}-2 \mathrm{Ti}-.6 \mathrm{Al}-.04 \mathrm{C}$ & $\gamma^{\prime \prime}$ precipitates \\
\hline
\end{tabular}

Table 2 Alloy compositions (wt.\%)

\begin{tabular}{cccccc}
\hline Alloy & Ni & Cr & Fe & Co & Nb \\
\hline MRL-1 & Bal. & 20.0 & -- & -- & 15.0 \\
MRL-2 & Bal. & 20.0 & 18.0 & -- & 15.0 \\
MRL-3 & Bal. & 20.0 & -- & 12.0 & 15.0 \\
MRL-4 & Bal. & -- & 18.0 & 12.0 & 15.0 \\
MRL-5 & Bal. & 20.0 & -- & 24.0 & 15.0 \\
MRL-6 & Bal. & 20.0 & 10.0 & -- & 15.0 \\
MRL-7 & Bal. & 12.0 & 18.0 & -- & 15.0 \\
\hline
\end{tabular}

Table 3 Effects of major alloying on eutectic secondary phases in $\mathrm{Ni}-\mathrm{Nb}$ systems

\begin{tabular}{clcc}
\hline Alloy & Major Alloying & $\begin{array}{c}\text { Secoundary } \\
\text { Phase }\end{array}$ & $\begin{array}{c}\text { Eutectic } \\
\text { Amount }\end{array}$ \\
\hline MRL-1 & high $\mathrm{Cr}$ & $\delta-\mathrm{Ni}_{3} \mathrm{Nb}$ & Moderate \\
MRL-2 & high $\mathrm{Cr}$, high $\mathrm{Fe}$ & Laves & Rich \\
MRL-3 & high $\mathrm{Cr}$, low $\mathrm{Co}$ & $\delta-\mathrm{Ni}_{3} \mathrm{Nb}$ & Moderate \\
MRL-4 & high $\mathrm{Fe}$, low $\mathrm{Co}$ & $\delta-\mathrm{Ni}_{3} \mathrm{Nb}$ & Little \\
MRL-5 & high $\mathrm{Cr}$, high $\mathrm{Co}$ & $\delta-\mathrm{Ni}_{3} \mathrm{Nb}$ & Moderate \\
MRL-6 & high $\mathrm{Cr}$, low $\mathrm{Fe}$ & Laves & Moderate \\
MRL-7 & low $\mathrm{Cr}$, high $\mathrm{Fe}$ & $\delta-\mathrm{Ni}_{3} \mathrm{Nb}$ & Moderate \\
\hline
\end{tabular}


approach the issue quantitatively, each alloying element was selected at two levels: $\mathrm{Cr}, 12$ and $20 \mathrm{wt} . \% ; \mathrm{Fe}, 10$ and $18 \mathrm{wt} . \%$; $\mathrm{Co}, 12$ and $24 \mathrm{wt} . \%$. A fixed $\mathrm{Nb}$ concentration of $15 \mathrm{wt} \%$ was the only hardening element added. In total there were 7 compositions selected, and their nominal chemistries are given in Table 2.

Raw materials of high purity laboratory grades were employed to prepare the heat of each alloy by vacuum induction melting (VIM). Conditioned ingots were charge into a directional solidification (DS) furnace that had the thermal control to produce single crystal superalloys. A slow draw speed of $15 \mathrm{~cm} / \mathrm{hr}$ was used, and all crystals produced had large elongated grain structure. Such a structure could be considered as the near equilibrium state during the solidification process. Minimum grain boundaries in the as-cast structure could simplify the analysis of phase relationship.

DS crystals were cut in both transverse (T) and longitudinal (L) cross sections for microstructural characterization and phase identification. Polished samples were examined under a Cambridge scanning electron microscope equipped with secondary electron (SE) and Xray energy dispersion detectors. Eutectic decomposition in each alloy generated constituent phases that had a significant difference on $\mathrm{Nb}$ concentration. The contrast between eutectic phases in SE images was apparent because of the heavy atomic weight of $\mathrm{Nb}$. The intermetallic phases such as Laves or $\mathrm{Ni}_{3} \mathrm{Nb}$ phases were much brighter than the Ni-rich $\gamma$ phase. Energy dispersion analysis of X-ray (EDAX) was carried out in coupling with the SE images to further differentiate the type of intermetallics. Quantitative chemical analysis performed by employing a microprocessor aimed at the participation of major alloying elements, $\mathrm{Cr}, \mathrm{Fe}$, and $\mathrm{Co}$.

The crystal structure of phases existing in every alloy was verified by the $\mathrm{X}$-ray diffraction method. The radiation employed was $\mathrm{Cu} \mathrm{K}_{\alpha}(=1.54060)$, and the diffraction angle $2 \theta$ for the observed peaks in each spectrum were examined and indexed numerically and graphically. To avoid the ambiguity caused by the texture of crystal growth, $\mathrm{X}$-ray diffraction was done on both transverse $(\mathrm{T})$ and longitudinal $(\mathrm{L})$ cross sections.

Phase transition temperatures, specifically the liquidus and the eutectic temperatures, were investigated by differential thermal analysis (DTA). The DTA cell was calibrated for temperature with pure $\mathrm{Al}$ and $\mathrm{Si}$, and the experimental accuracy was within $2^{\circ} \mathrm{C}$. The heating and cooling rate was set at $10^{\circ} \mathrm{C} / \mathrm{min}$. Duplicate tests were done on some alloys to check the variation of samples associated with the macrosegregation.

\section{RESULTS}

\section{$\underline{\text { SEM and EDAX }}$}

The as-cast structures examined by the secondary electron (SE) image under a scanning electron microscope are shown in Figure 1. A controlled slow cooling of directional solidification generates a crystal growth structure that is convenient for phase analysis. The preferred orientation for crystal growth in all alloys studied is $\langle 100\rangle$, similar to that in other superalloys. The dendrite morphology with $90^{\circ}$ intercepting dendrite arms appears clearly on the cross section of alloy crystals at low magnifications. As expected, the secondary phase with a high $\mathrm{Nb}$ content forms in every alloy, and their morphology is ready for observation with a bright atomic weight contract by SE imaging. 

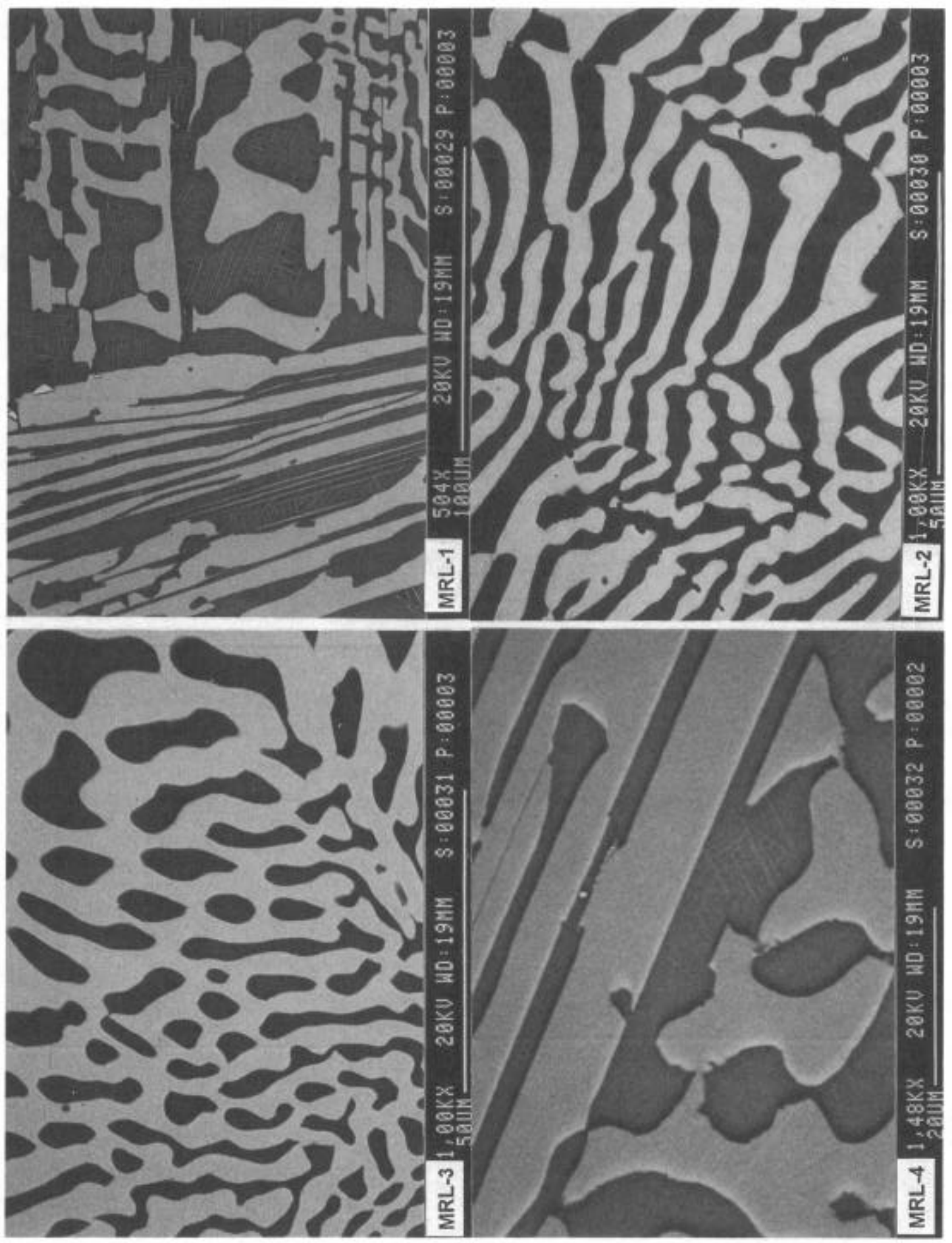

Figure 1 As-cast structures of $\mathrm{Ni}-\mathrm{Nb}$ alloy systems 


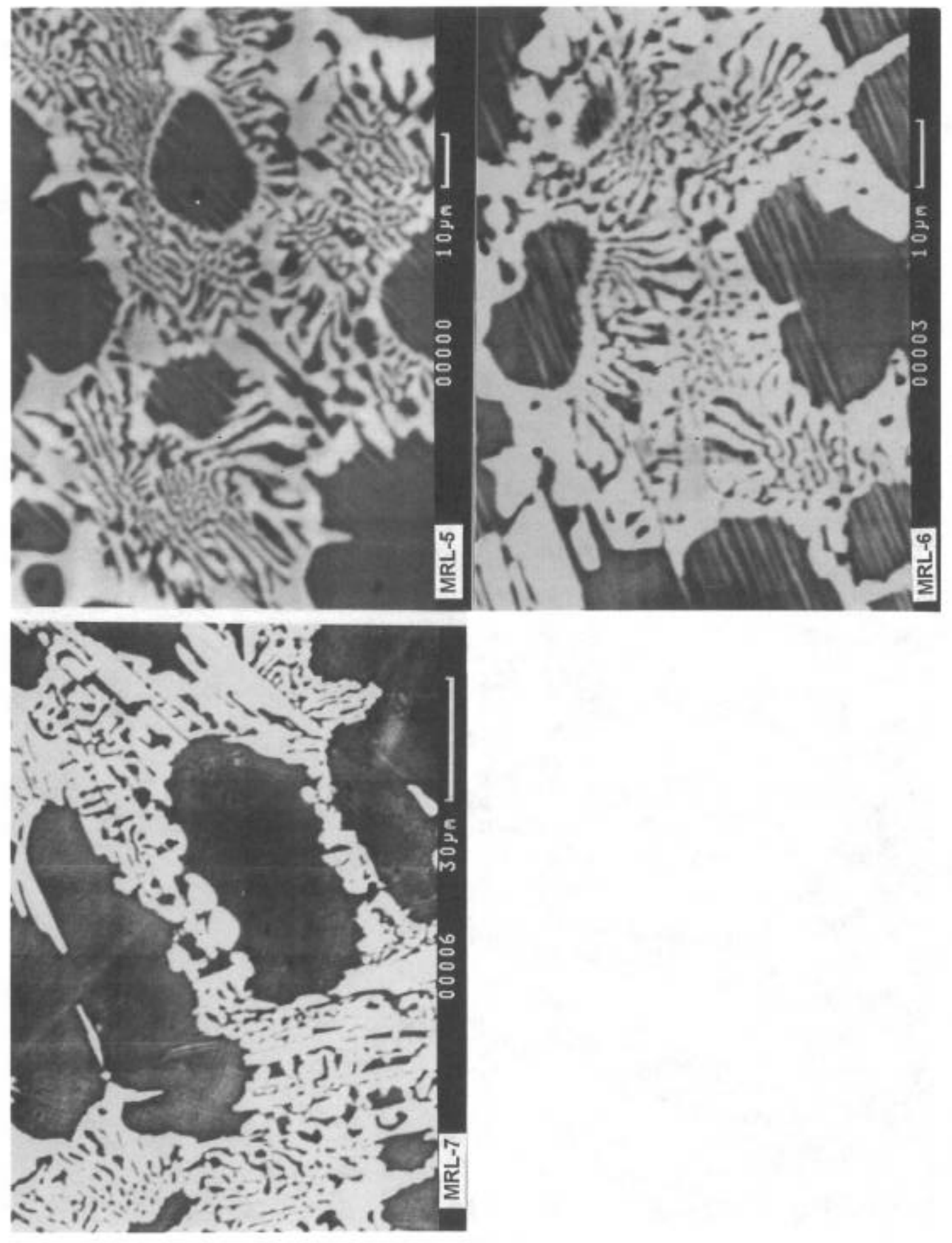

Figure 1 (conti.) 
Figure 1 shows that the eutectic decomposition takes place in the interdendritic regions at the end of solidification. All alloys in this study contain $15 \mathrm{wt} \% \mathrm{Nb}$ that is definitely above the solubility of $\mathrm{Nb}$ in the $\gamma$ matrix, but the eutectic reaction in each alloy and the correspondent composition of each phase are unknown. A qualitatively volume fraction of eutectic regions in every alloy is described in Table 3. Except alloy MRL-4 with a eutectic area less than $10 \%$, the rest alloys exhibit a substantial volume fraction of decomposed eutectic. The major eutectic constituent in alloys MRL-1 and MRL-2 is the $\gamma$ phase, which forms a continuous network around the isolated $\mathrm{Nb}$-rich phase in bright contrast. The rest alloys, including MRL-3, MRL-5, MRL-6, and MRL-7, have connected bright phases, and the fcc $\gamma$ phase becomes the secondary phase in the eutectic.

To identify Nb-rich secondary phase that forms eutectic constituents with the fec $\gamma$ matrix was performed by employing the energy dispersion analysis of X-ray (EDAX). Two types of EDAX spectrums were observed for those secondary phases, and both revealed a high $\mathrm{Nb}$ peak at about $20-30$ at. \% as seen in Figure 2. The major difference was $\mathrm{Cr}$ (and/or Fe) concentration that was balanced by $\mathrm{Ni}$. In the case that $\mathrm{Cr}$ is lean, the secondary phase is apparently the binary $\mathrm{Ni}_{3} \mathrm{Nb}(\delta)$. The $\mathrm{Cr}$ solubility in the $\delta$ phase never exceeds 5 at.\%, and so is $\mathrm{Fe}$. The other type of $\mathrm{Nb}$-rich secondary phase was a ternary intermetallic compound consisting of at least 3 different elements. The $\mathrm{Cr}$ content in this phase is above 10 at.\%. The crystal structure of the high $\mathrm{Cr}$ secondary phase was identified as Laves phase by X-ray diffraction, as reported in details later. Figure 2 compares the EDAX spectrums for alloy MRL-2 and MRL-7. A reduction of $\mathrm{Cr}$ from $20 \mathrm{wt} \%$ (MRL-2) to $12 \mathrm{wt} \%$ (MRL-7) in a high Fe (18 wt.\%) alloy changed the secondary phase of eutectic.

The SEM/EDAX results on the secondary phase of all alloys studied are summarized in Table 3. Five of seven alloys have the binary $\delta$ phase in their eutectic constituents, while the other two, MRL-2 and MRL-6 are Laves phase. Alloy MRL- 1 demonstrated that only Cr by itself did not cause Laves phase in the $\mathrm{Ni}-\mathrm{Nb}$ alloy system. A combination of high-content $\mathrm{Cr}$ and $\mathrm{Fe}$ is necessary for Laves phase formation, and $\mathrm{Cr}$ has more pronounced effect than $\mathrm{Fe}$ as referred to MRL- 6 and MRL-7. The Co addition within 24 wt. $\%$ simply substitutes Ni and does not affect the secondary phase $\left(\delta-\mathrm{Ni}_{3} \mathrm{Nb}\right)$.

\section{X-ray Diffraction and DTA}

Identifying the crystal structure of phases through X-ray diffraction offered additional evidences that the solidification process in 7 alloys studied was terminated by two-phase cutectic decomposition. Table 4 summarizes the observed peaks in the diffraction spectrums for all runs and the lattice plane indices of their corresponding phases. Only two intermetallic phases were identified, i.e., the hexagonal (C14 type) Laves phase and the othorambic (DOa type) $\delta-\mathrm{Ni}_{3} \mathrm{Nb}$ phase. In addition to the fcc $\gamma$ matrix phase, there was a single intermetallic phase detected in each alloy. Alloy MRL-2 that represented alloy 718 and alloy MRL-6 that contained a low level Fe formed Laves phase. The $\delta-\mathrm{Ni}_{3} \mathrm{Nb}$ phase was found in the rest alloys. No attempt was done in this work to determine the accurate lattice parameters of individual phases. The texture of crystal growth as reflected by the relative intensity of different peaks for a phase agreed with SEM morphology observation.

Differential thermal analysis has been extensively used to investigated the solidification behavior of Nb-bearing superalloys $[10,11]$. Unlike most previous studies in which there was only a little fraction of secondary phases existed, every alloy in this investigation contained a substantial amount of intermetallic phases. As a result, the DTA thermogram on cooling showed two 


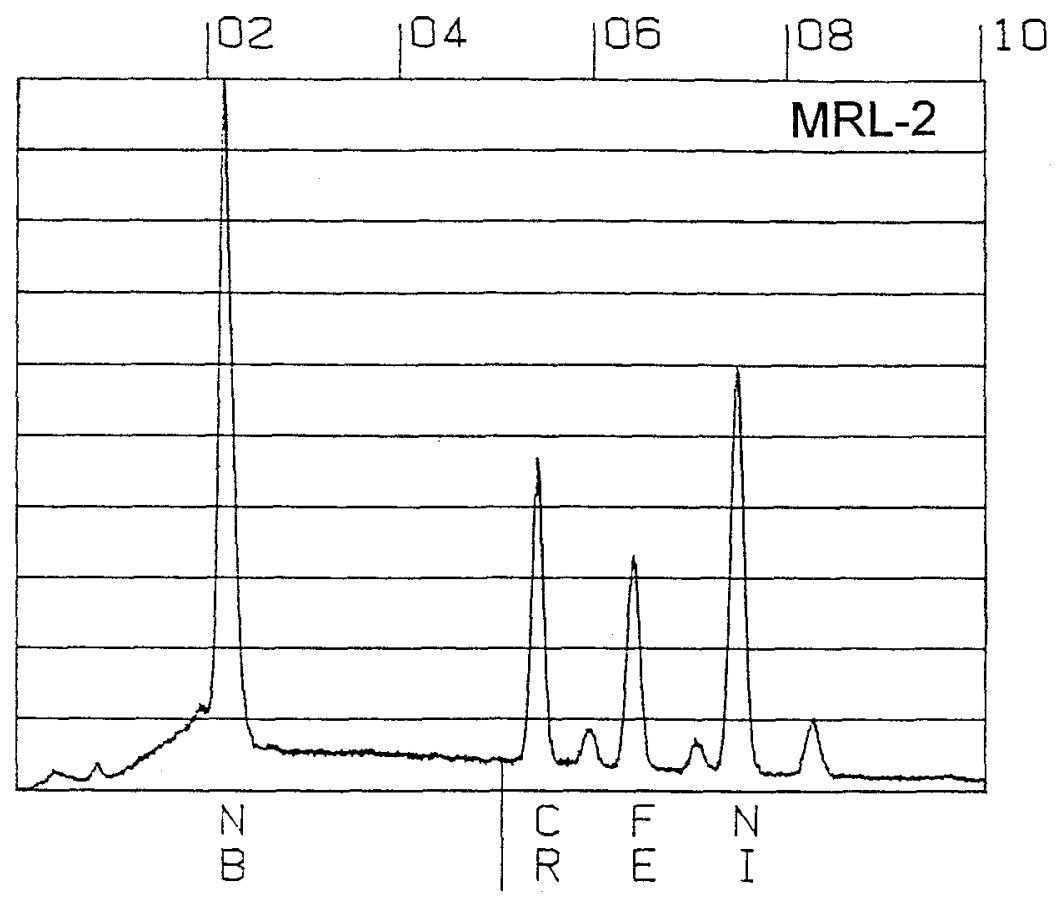

(a) Laves phase

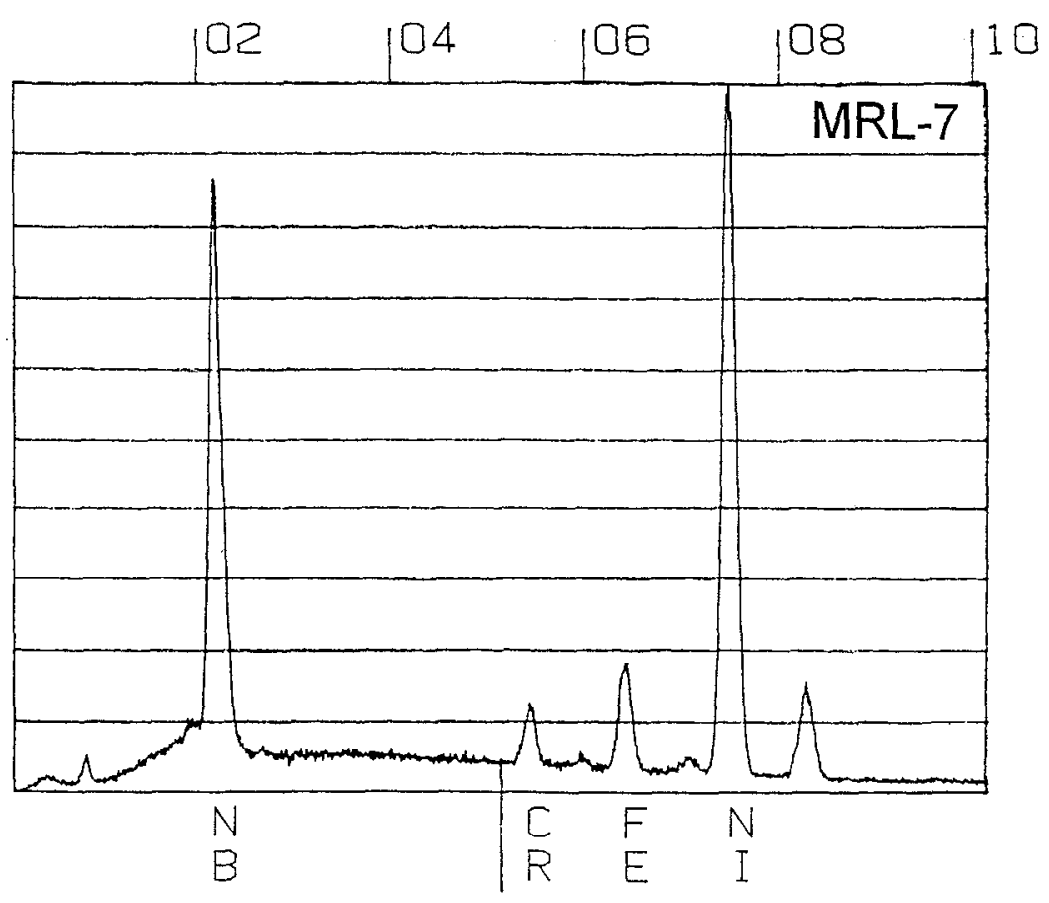

(b) $\delta-\mathrm{Ni}_{3} \mathrm{Nb}$

Figure 2 EDAX spectrums of eutectic secondary phase 
Table 4 Eutectic Phases identified by X-ray diffraction

\begin{tabular}{|c|c|c|c|c|c|c|c|c|c|c|c|c|c|c|c|}
\hline \multirow{3}{*}{ Phase } & \multirow{3}{*}{ Indices } & \multirow{3}{*}{$2 \theta$} & \multicolumn{13}{|c|}{ ALLOYS } \\
\hline & & & 1 & 1 & 2 & 2 & 3 & 3 & 4 & 4 & 5 & 5 & 6 & 6 & 7 \\
\hline & & & $\mathrm{T}$ & $\mathrm{L}$ & $\mathrm{T}$ & $\mathrm{L}$ & $T$ & $\mathrm{~L}$ & $\mathrm{~T}$ & $\mathrm{~L}$ & $\mathrm{~T}$ & $\mathrm{~L}$ & $T$ & $\mathrm{~L}$ & $\mathrm{~T}$ \\
\hline$\delta$ & 200 & 34.9 & $\sqrt{ }$ & & & & $\sqrt{ }$ & & $\sqrt{ }$ & $\sqrt{ }$ & & & & & $\sqrt{ }$ \\
\hline Laves & 110 & 37.4 & & & $\sqrt{ }$ & & & & & & & & $\sqrt{ }$ & $\sqrt{ }$ & \\
\hline$\delta$ & 002 & 39.8 & & $\sqrt{ }$ & & & & $\sqrt{ }$ & & & & & & & $\sqrt{ }$ \\
\hline$\delta$ & 201 & 40.4 & $\sqrt{ }$ & $\sqrt{ }$ & & & $\sqrt{ }$ & $\sqrt{ }$ & $\sqrt{ }$ & $\sqrt{ }$ & $\sqrt{ }$ & $\sqrt{ }$ & & & $\sqrt{ }$ \\
\hline Laves & 103 & 40.7 & & & $\sqrt{ }$ & $\sqrt{ }$ & & & & & & & $\sqrt{ }$ & $\sqrt{ }$ & \\
\hline$\delta$ & 020 & 42.5 & & $\sqrt{ }$ & & & & & $\sqrt{ }$ & $\sqrt{ }$ & & & & & $\sqrt{ }$ \\
\hline$\gamma$ & 111 & 43.6 & $\sqrt{ }$ & $\sqrt{ }$ & $\sqrt{ }$ & $\sqrt{ }$ & $\sqrt{ }$ & $\sqrt{ }$ & $\sqrt{ }$ & $\sqrt{ }$ & $\sqrt{ }$ & & $\sqrt{ }$ & $\sqrt{ }$ & $\sqrt{ }$ \\
\hline Laves & 112 & 44.1 & & & $\sqrt{ }$ & $v$ & & & & & & & $\sqrt{ }$ & $\sqrt{ }$ & \\
\hline Laves & 201 & 44.9 & & & $\sqrt{ }$ & $\sqrt{ }$ & & & & & & & $\sqrt{ }$ & $\sqrt{ }$ & \\
\hline$\delta$ & 012 & 45.3 & $\sqrt{ }$ & $\sqrt{ }$ & & & & $\sqrt{ }$ & & $\sqrt{ }$ & & $\sqrt{ }$ & & & $\sqrt{ }$ \\
\hline$\delta$ & 211 & 46.0 & $\sqrt{ }$ & $\sqrt{ }$ & & & $\sqrt{ }$ & & $\sqrt{ }$ & $\sqrt{ }$ & & & & & $\sqrt{ }$ \\
\hline Laves & 004 & 46.3 & & & $\sqrt{ }$ & & & & & & & & $\sqrt{ }$ & $\sqrt{ }$ & \\
\hline$\gamma$ & 200 & 50.8 & $\sqrt{ }$ & $\sqrt{ }$ & $\sqrt{ }$ & $\sqrt{ }$ & $\sqrt{ }$ & $\sqrt{ }$ & $\sqrt{ }$ & $\sqrt{ }$ & $\sqrt{ }$ & $\sqrt{ }$ & $\sqrt{ }$ & $\sqrt{ }$ & $\sqrt{ }$ \\
\hline$\delta$ & 022 & 59.6 & & $\sqrt{ }$ & & & & & & $\sqrt{ }$ & $\sqrt{ }$ & $\sqrt{ }$ & & & $\sqrt{ }$ \\
\hline$\delta$ & 221 & 60.2 & & $\sqrt{ }$ & & & & & $\sqrt{ }$ & & & & & & \\
\hline Laves & 213 & 69.5 & & & & & & & & & & & $\sqrt{ }$ & & \\
\hline Laves & 302 & 71.9 & & & & & & & & & & & $\sqrt{ }$ & & \\
\hline$\delta$ & 203 & 72.5 & & & & & & $\sqrt{ }$ & & $\sqrt{ }$ & & $\sqrt{ }$ & & & $\sqrt{ }$ \\
\hline$\delta$ & 400 & 73.9 & $\sqrt{ }$ & & & & $\sqrt{ }$ & & $\sqrt{ }$ & & & & & & \\
\hline$\gamma$ & 220 & 74.7 & $\sqrt{ }$ & $\sqrt{ }$ & $\sqrt{ }$ & $\sqrt{ }$ & $\sqrt{ }$ & $\sqrt{ }$ & $\sqrt{ }$ & $\sqrt{ }$ & $\sqrt{ }$ & & $\sqrt{ }$ & & $\sqrt{ }$ \\
\hline$\delta$ & 231 & 80.0 & & $\sqrt{ }$ & & & & $\sqrt{ }$ & $\sqrt{ }$ & $\sqrt{ }$ & & $\sqrt{ }$ & & & $\sqrt{ }$ \\
\hline
\end{tabular}

$2 \theta$ is the diffraction angles for the $\mathrm{Cu} \mathrm{K}_{\alpha}(=1.54060)$ radiation.

$\mathrm{T}$ : transverse section; L: longitudinal section.

Table 5 Effects of major alloying on eutectic secondary phases in Ni-Nb systems

\begin{tabular}{cccc}
\hline Alloy & $\begin{array}{c}\text { Eutectic } \\
\text { Constituents }\end{array}$ & $\begin{array}{c}\text { Liquidus } \\
\text { Temperature }\end{array}$ & $\begin{array}{c}\text { Eutectic } \\
\text { Temperature }\end{array}$ \\
\hline MRL-1 & $\gamma / \delta$ & $1308^{\circ} \mathrm{C}$ & $1256^{\circ} \mathrm{C}$ \\
& & $1299^{\circ} \mathrm{C}$ & $1240^{\circ} \mathrm{C}$ \\
MRL-2 & $\gamma /$ Laves & $1292^{\circ} \mathrm{C}$ & $1193^{\circ} \mathrm{C}$ \\
MRL-3 & $\gamma / \delta$ & $1301^{\circ} \mathrm{C}$ & $1227^{\circ} \mathrm{C}$ \\
MRL-4 & $\gamma / \delta$ & $\mathrm{NA}$ & $1226^{\circ} \mathrm{C}$ \\
\hline
\end{tabular}

NA: data are not available. 
distinct exothermic peaks, which corresponded to the liquidus and the eutectic temperatures. The data are listed in Table 5. While all alloys exhibit similar liquidus temperatures, the eutectic tempcrature of those alloys that form Laves phase (MRL-2) is low in comparison to that of other alloys. This observation definitely provides the fundamental explanation for the low incipient melting of Laves phase in the complicate compositions of commercial superalloys.

\section{DISCUSSION}

\section{Phase Diagram}

Laves phase does not appear in the binary $\mathrm{Ni}-\mathrm{Nb}$ phase diagram but exists in $\mathrm{Co}-\mathrm{Nb}, \mathrm{Cr}-\mathrm{Nb}$, and $\mathrm{Fe}-\mathrm{Nb}$ binary systems [12]. It is difficult to figure out the occurrence of an intermetallic phase in the $\mathrm{Ni}-\mathrm{X}-\mathrm{Nb}$ system based on the binary phase diagrams. As suggested by Sim, a polar phase diagram of $\mathrm{Nb}$ versus first long-period elements provides a consistent picture of various phase regions across the periodic table [13]. The individual alloying effect on a specific alloy system requires empirical data to set up ternary phase diagrams.

In the $\mathrm{Ni}-\mathrm{Cr}-\mathrm{Nb}$ ternary phase diagram [14], the Ni-rich $\gamma$ phase forms tie-lines with $\alpha-\mathrm{Cr}$ and $\delta$ $\mathrm{Ni}_{3} \mathrm{Nb}$ but not Lave phase $\mathrm{Cr}_{2} \mathrm{Nb}$. The two-phase region of $\alpha-\mathrm{Cr}+\delta-\mathrm{Ni}_{3} \mathrm{Nb}$ divides the ternary triangle into two parts, and $\gamma$ and Laves phases stay in different parts. It is impossible to have the $\gamma /$ Laves eutectic in the $\mathrm{Ni}-\mathrm{Cr}-\mathrm{Nb}$ ternary system, in spite of a high solubility of $\mathrm{Ni}$ in Laves phase. The results from alloy MRL-1 in which the $\delta-\mathrm{Ni}_{3} \mathrm{Nb}$ was detected re-verify the absence of Laves phase eutectic.

Quaternary Ni-Cr-Fe-Nb system was the key issue for the formation of Laves phase in Ni-base superalloys. Alloys MRL-2, MRL-6, and MRL-7 made the possible combinations of $\mathrm{Cr}$ and $\mathrm{Fe}$ alloying at high and low levels. A high level of $\mathrm{Cr}$ and a certain amount of $\mathrm{Fe}$ is the necessary condition for Laves phase (MRL-2 \& MRL-6). If $\mathrm{Cr}$ addition is reduced to $12 \mathrm{wt} \%$, then Laves phase can be avoid. A similar empirical observation has been reported in alloy 718 [8].

Based on the polar phase diagram of $\mathrm{Nb}$, Laves phase is expected at $24 \mathrm{wt} \%$ Co but not at 12 wt.\% Co in the ternary Ni-Co-Nb system. A high level of $\mathrm{Cr}$ in alloys MRL-3 and MRL-5 definitely promotes Laves phase. However, the eutectic in both alloys only consists of $\delta$ $\mathrm{Ni}_{3} \mathrm{Nb}$. The Co solubility in the HCP $\delta$ phase is known to be very high and may substitute for more than $60 \% \mathrm{Ni}$. The $\mathrm{Ni}$-rich $\gamma$ and $\mathrm{Nb}$-rich $\delta$ phases are separated by the $\delta$ phase whose $\mathrm{Ni} / \mathrm{Nb}$ ratio $(\sim 3)$ is higher than that of Laves phase $(\sim 2)$.

Alloy MRL-4, a Ni-Fe-Co-Nb quaternary system, develops the least fraction of $\gamma / \delta$ eutectic. Isolated $\delta$ particles in the as-cast structure suggested a high solubility of $\mathrm{Nb}$ in the $\mathrm{Cr}$-free $\mathrm{Ni}$ base matrix. Laves phase is unlikely to form unless the alloy becomes a Fe-base system (e.g., alloy 909).

\section{Alloy Design}

The formation of TCP phases has been a critical topic for designing a useful superalloys. Because of chemistry complex, the base thermodynamic information, such as binary or ternary phase diagram, can only provide a simple reference as the starting point. Fmpirical trial is the most effective method to develop a new alloy for specific purposes. Nevertheless, some of empirical rules can be summarized and rationalized in conjunction with alloy chemistry theory. 
The main reason why alloy 718 contains a high level $(\sim 18 \mathrm{wt} . \%)$ of $\mathrm{Fe}$ is to achieve a high strength at low and intermediate temperatures up to $650^{\circ} \mathrm{C} \mathrm{[2].} \mathrm{The} \mathrm{strength} \mathrm{enhancement} \mathrm{is}$ directly related with the precipitate coherency determined by the lattice mismatch between $\gamma / \gamma^{\prime \prime}$ phases. A low Fe version of alloy 718 was reported to have better stress rupture strength, but the improvement of temperature capability was limited. Complete Fe-free 718 might get rid of Lave phase; how ever its strength becomes too low to be practically useful.

One of effective approaches to eliminate Laves phase is the reduction of $\mathrm{Cr}$ alloying (12 wt.\%). The $\mathrm{Cr}$ addition in superalloys provides high temperature oxidation and corrosion resistance as well as the solubility control of precipitation elements. More additions of precipitation elements can compensate the strength loss caused by $\mathrm{Cr}$ reduction as done in PWA 1472 [9].

A novel approach taken in Rene' $220 \mathrm{C}$ replaced Fe by an optimum level of $\mathrm{Co}$. The data of this study strongly support that Lave phase would not appear in this type of alloys. Another important consequence of $\mathrm{Co}$ alloying that has little relation with Laves phase is the significant improvement of stress rupture life at temperatures above $650^{\circ} \mathrm{C}$.

\section{CONCLUSIONS}

The terminal solidification constituent of a series of Ni-base alloys containing various combinations of major alloying elements and excessive $\mathrm{Nb}$ has been investigated. The additions in two levels of major alloying, including $\mathrm{Cr}, \mathrm{Fe}$, and $\mathrm{Co}$, resulted in two types of eutectic decomposition to finish alloy solidification process. A high level of $\mathrm{Cr}(20 \mathrm{wt} . \%)$ together with a certain amount of $\mathrm{Fe}(10 \mathrm{wt} . \%$ or above) will cause the formation of Laves phase. Otherwise the binary $\gamma / \delta$ eutectic will appear at a high $\mathrm{Nb}$ concentration. The substitution of $\mathrm{Co}$ for $\mathrm{Ni}$ (up to $24 \mathrm{wt} . \%$ ) has little effect on the phase formation.

\section{ACKNOWLEDGMENTS}

The authors would like to thank their colleagues, Dr. Li-Jiaun Lin, Dr. Ming-Sheng I.eu, and Mr. Jen-Dong Hwang, for their technical support in X-ray diffraction, DTA tests, and crystal preparation, respectively. Valuable discussion with Dr. Tsang-Sheau Lee, Chung-Shan Institute of Science \& Technology, is highly appreciated.

\section{REFERENCES}

1. H.L. Eiselstein and D.J. Tillack, "The Invention and Definition of Alloy 625", Superalloy 718, 625 and Various Derivatives, ed. by E.A. Loria, 'TMS, 1991, pp. 1-14.

2. H.L. Eiselstein, "Metallurgy of a Columbium-Hardened Nickel-Chromium-Iron Alloy", Advances in the Technology of Stainless Steels, ASTM STP 369, 1965, pp. 62-79.

3. K.-M. Chang and A.H. Nahm, "Rene'220: $100^{\circ}$ F Improvement over Alloy 718", Superalloy 718, ed. by E.A. Loria, TMS, 1989, pp. 631-646.

4. O.W. Ballou and M.W. Coffey, "History of Cast INCO 718", Superalloys 1988, ed by D.N Duhl, et al. TMS, 1988, pp. 469-473. 
5. M.J. CIESLAK, G.A. Knorovsky, T.J. Headley, A.D. Roming, JR., "The Solidification Metallurgy of Alloy 718 and Other Nb-Containing Superalloys", Superalloy 718, ed. by E.A. Loria, TMS, 1989, pp. 59-68.

6. K.-M. Chang, U.S. Patent 4,981,644, Jan. 1, 1991.

7. S.T. Wlodek and R.D. Field, "The structure of Rene'220C", Superalloys 1992, ed. by S.D. Antolovich, et al. TMS, 1992, pp. 477-486.

8. S.M. Snyder and E.E. Brown, U.S. patent 4,750,944, Jun. 14, 1988.

9. J.F. Radavich, "Metallography of a High Strength Modified 718 Alloy - PWA 1472", Superalloy 718, 625 and Various Derivatives, ed. by E.A. Loria, TMS, 1991, pp. 865-877.

10. W.D. Cao, R.L. Kennedy, and M.P. Willis, "Differential Thermal Analysis (DTA) Study of the Homogenization Process in Alloy 718", Superalloy 718, 625 and Various Derivatives, ed. by E.A. Loria, TMS, 1991, pp. 147-160.

11. G.K. Bouse, "Application of a Modified Phase Diagram to the Production of Cast Alloy 718 Components", Superalloy 718, ed. by E.A. Loria, TMS, 1989, pp. 69-77.

12. T.B. Massalski, Binary Alloy Phase Diagram, ASM, 1986.

13. C.T. Sims and W.C. Hagel, The Superalloys, John Wiley \& Sons, 1972.

14. A. Taylor, J. Met., Oct. 1956, pp. 1356-1362. 